\title{
An Evaluation of the Junior Master Gardener Program in Third Grade Classrooms
}

\author{
Amy E. Dirks ${ }^{1}$ and Kathryn Orvis ${ }^{2}$
}

ADDITIONAL INDEX WORDS. school garden, science education, horticultural education, youth

\begin{abstract}
Summary. Studies have shown gardening to have the potential to influence students in several positive ways. The hands-on and informal learning that occurs in these outdoor areas can be incorporated into all areas of the curriculum, fostering environmental awareness and increased interest in science. Junior Master Gardener (JMG) was chosen to be evaluated in 14 Indiana third grade classrooms as little formal classroom usage data exists for the program. It was hypothesized that the use of the program could help improve agriculture awareness and knowledge in youth. Quantitative and qualitative instruments and observations were utilized in a effort to evaluate knowledge gain and change of attitude towards the topics covered by the JMG curriculum; science, horticulture, and the environment. Student pre- and posttest results indicated overall significant gains in knowledge and attitudes. Performance was not attributed to student age, gender, race, or location of the school, although those schools with a garden achieved more positive gains in attitude and specific performance varied according to classroom. Qualitative data also indicated that the students enjoyed the program, shared what they learned with others, and wanted to participate in more JMG and gardening type activities. Teachers indicated that they were satisfied with the program in their classrooms and planned to reuse their JMG materials for future classes.
\end{abstract}

$\mathrm{P}$ ants and the process of growing plants can be used as a focus for any number of educational subjects. Horticulture, plant science, and gardening can be integrated into every subject area of the elementary school curriculum such as science, mathematics, language arts, and social studies. Horticultural practices and gardening in the classroom can also be used by educators to meet statemandated requirements in multiple subject areas (Barron, 1993; Cavalier, 1987; Dwight, 1992; Gwynn, 1988; Markle, 1991; Nelson, 1988; Salisbury, 1989; Stetson, 1991).

School gardens were common at the beginning of the 20th century, but

\footnotetext{
${ }^{1}$ Dept. of Youth Development and Agriculture Education, Purdue University, 615 W. State St., West Lafayette, IN 47907.

${ }^{2}$ Depts. of Youth Development and Agricultural Education, and Horticulture and Landscape Architecture, 615 W. State St., West Lafayette, IN 47907.

The authors wish to thank and recognize the sponsor of this research, the North Central Region-Sustainable Agriculture Research and Education Program. Junior Master Gardener, JMG, and associated logos are registered service marks of the Texas Cooperative Extension, The Texas A\&M University System.

${ }^{1}$ Former Graduate Research Assistant.

${ }^{2}$ To whom correspondence should be addressed; e-mail address: orvis@purdue.edu
}

their occurrence became scarce due to various reasons, including changes in teaching philosophies (Babcock, 1909; Fang, 1995; Lyttle, 1998; Shair, 1999). Current changes in educational philosophies including utilization of hands-on and experiential learning, as well as the importance of environmental science and nutrition education, are generating renewed interest in school gardening programs. Teachers may facilitate gardening activities without the ability to integrate them into existing curriculum, academic standards, and an already busy schedule. These situations often lead to frustration and ultimately the demise of school gardening. Many search for techniques to introduce and incorporate gardening into existing curricula. Teachers and administrators are concerned about the educational merits of gardening, such as how well it fits within academic standards or standardized testing, as well as logistical requirements such as funding and administrative support (DeMarco, 1997). Although there are various books, activity manuals, websites, and programs available for youth gardening, many of these programs have not been evaluated for their use in the classroom. 
The JMG program is a youth gardening program that has the capacity to address some of the educational concerns of teachers and administrators for implementing and utilizing school gardens. Developed at Texas A\&M University, the program incorporates many areas related to gardening such as science and environmental education, along with providing opportunities for youth to develop responsibility and leadership skills (Welsh et al., 1999).

The overall objective of this research was to evaluate the program in a formal classroom setting. A series of activities were specifically chosen for third grade classrooms and utilized for quantitative and quantitative assessment of science achievement and attitudes toward science, horticulture, and the environment. Second, we wished to understand through student and teacher evaluations and observations, how the program fit with the rest of the curriculum and how participants reacted to it.

\section{Materials and methods}

A mixed methods approach was used to address formative, dynamic, and summative data through both quantitative and qualitative methods. This was achieved through pre-post testing using a two-part test, as well as a post only survey, designed for this study. Data were entered and analyzed using SAS (PC-SAS version 8; SAS Institute, Cary, N.C.). Descriptive statistics used to analyze the data included: frequencies, medians, modes, ranges, percentages, and standard deviations. An alpha level of 0.05 was used for significance along with a more conservative alpha of 0.0036 , which was adjusted using the Bonferroni method (Moore and McCabe, 1999). This adjustment is a more stringent measurement for multiple comparisons and has a lower incidence of Type I errors. The results of the statistical analysis were used to organize, summarize and interpret the data.

Fourteen third grade teachers and students $(\mathrm{N}=277)$ in their classrooms participated in this study, representing 11 schools in 10 counties of Indiana. Participating classrooms represented several demographic settings which included rural, small town, large town, and urban fringe. Participating students included some minorities (African American $\mathrm{n}=6$, Asian $\mathrm{n}=5$, Hispanic $\mathrm{n}=6$, and Native American $\mathrm{n}=2$ ). The self reported average age of the students was 8.7 years and the gender of the students was evenly distributed between female $(\mathrm{n}=139)$ and male $(\mathrm{n}=136)$.

Participating teachers attended a training session that familiarized them with the JMG program, as well as research materials and procedures. JMG curriculum, lesson plans, and supplies were provided to participating classrooms at training. Teachers gained experience in using the curriculum through participation in sample activities. Lesson plans were created by the researcher for set of activities specified to be used in the study. Indiana State Academic Standards for Math, Language Arts, Social Studies, and Science were matched to all individual and group activities in Level 1 JMG manuals, including the subset used for this study. Following the training, teachers implemented the program for 10 to 12 weeks in Spring 2003.

Since no evaluation instruments specific for JMG were publicly available, and available standardized inventories were not at the appropriate age level or did not test the particular topics of interest for this study, evaluation tools were developed for this research. Several studies were utilized in the development of the quantitative instrument for measuring knowledge gain (Ary et al., 2002; Earthman et al., 1999; Leeming and Dwyer, 1995) and for the quantitative instrument evaluating attitudes using a modified Likert scale (Arnold et al., 1967; Leeming and Dwyer, 1995; Musser and Diamond, 1999; Musser and Malkus, 1994; Skelly and Zajicek, 1998; Trobe and Acott, 2000; Trochim, 2001; Waliczek and Zajicek, 1999). In addition, a set of questions had been developed previously for an Indiana JMG evaluation by K. Orvis and C. Shelbourne (unpublished). The purpose of results reported in this article was to assess the use of JMG in the classroom; therefore, discussion of the development and assessment of the instruments themselves will not be discussed.
The instruments used for quantitative data were designed to measure student's short term knowledge gain and short term changes in attitudes concerning gardening, science, and the environment. The instrument for assessing knowledge gain consisted of 16 multiple choice and matching questions related to topics in each of the eight JMG chapters. Attitudes were assessed through a simplified Likert scale to evaluate 28 statements about gardening, science, and the environment. In addition, two qualitative postonly program surveys were created for both student and teachers. This survey was composed of open ended questions designed to help assess the effectiveness of the program. Classroom observations were also utilized in addition to the instruments and surveys. Observations were based on a non-participatory role where classrooms were visited to observe the teacher and students participating in a JMG lesson or activity. The classroom setting, the teacher's teaching style, the student's behavior, and the teacher's behavior were recorded. Each participating classroom was visited at least once, and 12 of the 14 were visited twice.

Content and age appropriateness of the instruments was evaluated by a program evaluation expert and a youth development extension specialist with the Department of Youth Development and Agricultural Education, as well as a youth literacy professor in the School of Education at Purdue University. In addition, extension specialist with expertise in plant science and two county extension educators familiar with the program evaluated the instruments for content validity.

\section{Results}

Pre- and postquantitative instruments for knowledge gain and attitudes were analyzed as matched sets for 265 of the 277 students participating in the study. An overall significant positive change in knowledge and attitude scores from preprogram to postprogram was measured (Table 1). Paired

Table 1. Overall results of knowledge and attitude instruments used to evaluate effectiveness of Junior Master Gardener in Indiana third grade classrooms.

\begin{tabular}{lcccc}
\hline & Pretest & Posttest & Difference & $P$ \\
\hline Knowledge & 8.37 & 10.24 & 1.87 & $<0.0001^{\mathrm{z}}$ \\
Attitude & 2.57 & 2.74 & 0.17 & $<0.0001^{\mathrm{z}}$ \\
\hline${ }^{2}$ Significant at alpha $=$ & 0.05 and at the Bonferroni adjusted alpha $=0.0036$.
\end{tabular}


$t$ tests showed several classrooms to have significant positive differences between pre- and posttests for knowledge gain. Assessment of attitudes was also analyzed by matched pairs $t$ test, comparing each student's average attitude score pre- and postprogram. Comparisons of scores according to differences in classroom, gender, race, region (rural vs. suburban, etc.), and whether the school had a school garden or outdoor classroom, were analyzed using analysis of variance (Table 3). For the knowledge instrument significant difference occurred between classrooms $(P<0.0001)$. Significant differences were also found for the presence of a school garden $(P$ $<0.0001)$.

Table 3 gives an overview of the questions in the post-only student qualitative instrument. Student evaluations were received from 11 of the 14 classrooms, comprising a total of 209 student's responses. Of the four openended questions and two closed-ended questions, responses were categorized by same or similar responses and tallied by the researcher.

The teacher post-only qualitative instrument asked the teachers three open-ended and three closed-ended questions concerning their experience with the program. An overview can be found in Table 4 for nine of 14 teachers.

Classroom observations of JMG lessons were made for all classrooms by the graduate assistant. Observations in the classroom during the JMG activities were useful and helped to understand the results of the quantitative data. Assertions were made from each observational visit with a classroom and condensed to overall assertions of different topics. They were also made before analysis of the quantitative data began. The following are the areas of assertions common to all the observations.

1. Many factors affected the way the JMG program was presented: teaching technique (inquiry based), teacher interest and perceived background knowledge, classroom size, and access to or presence of a school garden.

2. School gardening increased with the use of the program.

3 . The program was adapted into current curriculum.

4. The JMG manuals were valued by teachers and students.

Table 2. Results of analysis of variance for group comparisons among third grade participants in Indiana $(\mathrm{N}=277)$ utilizing Junior Master Gardner in their classroom.

\begin{tabular}{lrrrrrrr}
\hline \multirow{2}{*}{$\begin{array}{l}\text { Comparison } \\
\text { groups }\end{array}$} & \multicolumn{3}{c}{ Knowledge instrument } & & \multicolumn{2}{c}{ Attitude instrument } \\
\cline { 2 - 3 } \cline { 7 - 8 } & df & F & $P$ & & F & $P$ \\
Classroom & 13 & 6.75 & $<0.0001^{*}$ & & 3.33 & $<0.0001^{*}$ \\
Gender $^{z}$ & 1 & 0.04 & 0.833 & & 0.07 & 0.786 \\
Region $^{\mathrm{y}}$ & 4 & 1.00 & 0.408 & & 2.45 & 0.047 \\
Age $^{\mathrm{x}}$ & 3 & 0.68 & 0.566 & & 1.50 & 0.214 \\
Race $^{\mathrm{w}}$ & 7 & 1.66 & 0.119 & & 1.18 & 0.318 \\
School garden $^{\mathrm{v}}$ & 1 & 1.50 & 0.214 & & 3.33 & $<0.0001^{*}$ \\
\hline
\end{tabular}

${ }^{\mathrm{z}}$ Male or female.

'Rural; town $(<10,000)$; city $(10,000-50,000)$; suburb; or city $(>50,000)$.

$x, 9,10$, or 11 years old.

"African American, Asian, Hispanic, Native American, White, or Other

Yes or no.

*Significant at alpha $=0.05$

Table 3. Summary of most common student responses to open-ended post-only student qualitative instrument $(\mathrm{N}=209)$ for third grade students in Indiana participating in Junior Master Gardener (JMG).

1. Name one new thing you learned while doing JMG.

$\mathrm{n}=19 \quad$ We can not live without plants

$\mathrm{n}=17 \quad$ How to plant seeds, flowers or plants

$\mathrm{n}=15 \quad$ Information about insects (types, difference between good and bad)

$\mathrm{n}=12 \quad$ Worms and composting

2 What was your favorite JMG activity and why?

$\mathrm{n}=41 \quad$ Planting or growing plants

$\mathrm{n}=28 \quad$ Gas Gobblers (gas exchange and importance of plants activity)

3 If you did a community service project, what did you do and what did you learn? $\mathrm{n}=46$ Planting flowers or garden for the school or community

$\mathrm{n}=35 \quad$ Cleaning up an area or picking up litter

4 Did you talk with your parents and/or family about what you did or learned with JMG?

$$
\mathrm{n}=135 \text { Yes } \mathrm{n}=83 \quad \text { No }
$$

5 Would you like to participate in more JMG programs?

$\mathrm{n}=171 \quad$ Yes $\mathrm{n}=40 \quad$ No

6 Write any other things about JMG that you think are important.

$\mathrm{n}=63$ Positive statements about the environment

$\mathrm{n}=56$ Statements about plants, planting, caring for or growing plants

$\mathrm{n}=20 \quad$ Positive statements about JMG program

Others: Composting, insects, soil, importance of plants for gas exchange

5. Student interest in the JMG program was high.

\section{Discussion}

Overall results from the quantitative knowledge instrument indicated significant gains in knowledge related to topics covered in the JMG program for participating classrooms when comparing pre- and postprogram scores. This supports the conclusion that the students learned information from participation in the JMG program. In addition, results indicated overall positive change in attitudes towards science and agriculture when measure pre-and postprogram with the attitude quantitative instrument. Because the test is a simplified version of a Likert scale specifically adapted for the developmental stage of third graders, results do not indicate how strongly students' attitudes changed.

Results of the post-only student qualitative evaluations showed an overall positive response towards the JMG program. An interesting finding was that students learned that they could not live without plants. This contradicts previous research where Relf et al. (1992) found that despite environmental education, less than 50\% of the respondents ( $46 \%$ ) believed that the natural world is essential to their well-being. This information was most likely gained through specific activities 
Table 4. Summary of most common teacher responses to open-ended post-only teacher qualitative instrument $(\mathrm{N}=9)$ from teachers of third grade classrooms in Indiana participating in a Junior Master Gardener (JMG) study.

1 List one attitude or behavior change that you observed in the youth during or following the utilization of the JMG curriculum.

$\mathrm{n}=5 \quad$ Interest and excitement for learning or learning science was evident

Others: Students showed pride in themselves; Students matured and demonstrated responsibility individually and as a group

2 What was your favorite JMG activity and why?

$\mathrm{n}=3 \quad$ Liked all activities utilized

$\mathrm{n}=2 \quad$ Gas Gobblers (activity teaching gas exchange and importance of plants)

$\mathrm{n}=2 \quad$ Paper Pot (use newspaper to make 'plantable' pots to start seeds)

$\mathrm{n}=\mathrm{l} \quad$ Community Service activity in addition to all other activities

$\mathrm{n}=1 \quad$ Activity involving food and plant parts

3 How often did you use JMG?

$\mathrm{n}=2 \quad$ Weekly

$\mathrm{n}=2 \quad$ Two to three times weekly

$\mathrm{n}=5 \quad$ Daily

4 Did you have any helpers or volunteers with/for the program? If yes, what was their affiliation?

$\mathrm{n}=4 \quad$ No, did not utilize an assistant or classroom helper

$\mathrm{n}=5 \quad$ Yes, utilized a classroom helper or volunteer which included:

- Teaching assistant, class intern, volunteer landscaper, parent

6 Other comments about the JMG program or the research project?

$\mathrm{n}=3$ Continued use of the JMG program in their classroom

$\mathrm{n}=$ most Enjoyment of program

Combined areas of improvement listed three main topics:

- Longer period of time to use the program

- Different layout for teacher/leader manual to incorporate youth manual

- Concern with expense of program

that focus on the many things made from plants, the importance of plants to our diet, and the interdependence of animals and plants for exchange of oxygen and carbon dioxide. One component of this JMG in the classroom intervention was to incorporate a community service activity. In the post program student instrument, youth were able to identify that they had done a service project and what that project was; many mentioned cleaning up areas of litter and weeds, and planting a garden. This indicates that the program has the capacity to increase service-learning and impact students to connecting to their communities. Another deduction from the evaluation and observations indicated the students enjoyed doing the activities. Several students indicated that they shared what they learned with others. This indicates that using a hands-on gardening program, such as JMG, in the classroom can inspire youth to be interested in learning, especially in learning science.

Increased knowledge and positive attitudes suggests that the program has academic merit as well as the potential to increase attitudes in the topic areas of science, agriculture and the environment. This implies that the JMG program can be used effectively in the classroom to teach topics in science, agriculture and environmental education in an interdisciplinary manner. Furthermore, students reported "having fun" while learning through the use of JMG activities and curriculum. This does explicitly imply that the curriculum was easy for the students; however the giving students a positive hands-on experience with science helps alleviate misconceptions regarding difficulty and lack of interest.

The teacher evaluations revealed many positive responses, especially focusing on positive student changes in behavior and that they themselves enjoyed the program. Teachers reported that students were excited and interested in learning when utilizing the JMG program. The teachers' and students' positive responses strengthen the probability that the teachers will use the curriculum and supplies again with future classes. Although the teachers received the entire curriculum and many supplies for implementing the program, they did share concerns regarding expenses involved in starting JMG in a classroom.

Several teachers indicated that they replaced all or some of their science curriculum with the JMG curriculum. In addition, several teachers were successful at integrating JMG into other subject areas such as math and language arts. One teacher incorporated language arts into the JMG concepts by having the students read aloud the chapter information and then would make the student's weekly spelling lists from that chapter. Another example of integration of JMG into all aspects of the classroom was through a specific lesson (composting) that was extended into classroom project. Each day over 2 weeks, the students from this particular classroom would collect their leftover food scraps (that could be composted) at lunchtime, weigh and record the type of scraps and record data in a journal. At the end of the 2 weeks, the students used math skills to calculate the average weight of food they wasted in 1 week, and to estimate the amount wasted by all the third grade classrooms in 1 week and by their classroom alone in 1 month. Students used language arts skills to write a report recommending ways that students could waste less and items that could be replaced on the school lunch menu.

Having a school garden or outdoor classroom was not a requirement for this program. However, more than half of the participating classrooms had access to a garden or outdoor classroom $(\mathrm{n}=8)$. The remaining teachers indicated interest in creating a school garden or outdoor classroom alongside participation in the JMG program. Classrooms with established gardens utilized these areas for JMG activities, yet some classrooms without formal gardens initially did not confine their activities indoors. These teachers often found ways, such as building weather stations around the school, to incorporate the outdoors into their JMG lessons. At the end of the program five of the seven "gardenless" classrooms had established an area for their students to garden.

Some schools chose to do their community service projects as part of the JMG curriculum in the local community at places such as the fire station or community center. For other 
classrooms, their community service projects were done at the school. Many of these service activities consisted of cleaning areas of litter and weeds or planting flowers and vegetables. These activities seemed to influence the creation of the additional school gardens during the program.

This study utilized evaluation instruments created by the researchers, which may limit the extent to which conclusions can be made from results reported here. It is possible that some test questions may have been overly difficult for the age group utilized or contained vocabulary or concepts that were not covered within the JMG program. Knowledge gain may have been from memorization or guessing. To test for higher levels of learning the quantitative instrument(s) could be changed to application or story problem based testing. In addition, due to the relatively short duration of the program (10-12 weeks) attitude changes while significant, were small. The attitude quantitative instrument may have targeted the values of the students, which are formed over long periods of time and are more resistant to change.

Classrooms participated on a voluntary basis by teachers or principals with interest in youth gardening. Some participating teachers had school gardening experience, while others had little previous experience. These variables may have influenced student and teacher responses in this study. Some schools already had existing school gardens or gardening programs, which may have influenced student and teacher attitudes towards gardening and started at an already positive attitude level prior to the program implementation. In addition, participants in this study are from mainly rural or suburban areas, where students may have had previous exposure to agriculture and gardening. This may have led to high levels of knowledge and attitudes towards gardening and the environment. Also, because of these locations, demographics were not very diverse among classrooms.

While the scope of this study may be limited, overall results are in agree- ment with previous reports indicating that gardening can successfully be used in the classroom and has the capacity to positively influence students in their learning, especially for science related topics. The program was not only a motivating factor for classrooms to utilize current garden areas, but also facilitated the creation of school or community gardens. The program's ease of use as indicated by the teachers, and students' level of enthusiasm for learning while participating in the JMG program make it an viable option for incorporation into formal learning settings.

\section{Literature cited}

Arnold, W.E., J.C. McCroskey, and S.V. Prichard. 1967. The Likert-type scale. Today's Speech 15:31-33.

Ary, D., L.C. Jacobs, and A. Razavieh. 2002. Introduction to research in education. 6th ed. Wadsworth/Thomson Learning, Belmont, Calif.

Babcock, E.B. 1909. Suggestions for garden work in California schools. Univ. California Agr. Expt. Sta. Ext. Publ. No. 46.

Barron, J. 1993. The greening of St. Patrick's pathways. Ontario J. Outdoor Educ. 5(4):5-7.

Cavalier, D. 1987. How zucchini won 5 th grade hearts. Children Today 16(3):1821 .

DeMarco, L. 1997. The factors effecting elementary school teachers' integration of school gardening into the curriculum. PhD Diss., Virginia Poly. Inst. and State Univ., Blackburg.

Dwight, E. 1992. A tree grows in Harlem. Amer. School Board J. 179(6):31-33.

Earthman, E., L.S. Richmond, D.J. Peterson, M.S. Marczac, and S.C. Betts. 1999. Adapting evaluation measures for 'hard to reach' audiences. CyferNet: Children, youth, and families education and research network. Univ. Arizona Coop. Ext. Serv., Tucson.

Fang, W. 1995. The case for more: High school gardens. Urban Ag. Notes. 18 Sept. 2002. <http://www.cityfarmer.org/highschool77.html>.

Gwynn, M.L. 1988. A growing phenomenon. Sci. Children 25(7):25-27.
Leeming, F.C. and W.O. Dwyer. 1995. Children's environmental attitude and knowledge scale: Construction and validation. J. Environ. Educ. 26(3):22-31.

Lyttle, M. 1998. Taking root. Educ. Weekly 17(41):30-35.

Markle, S. 1991. Green growers. Instructor 100(7):48-51.

Moore, D.S. and G.P. McCabe. 1999. Introduction to the practice of statistics. 4th ed. Freeman, New York.

Musser, L.M. and K.E. Diamond. 1999. The children's attitudes toward the environment scale for preschool children. J. Environ. Educ. 30(2):23-30.

Musser, L.M. and A.J. Malkus. 1994. The children's attitude toward the environmental scale. J. Environ. Educ. 25(3):22-26.

Nelson, C.J. 1988. Harvesting a curriculum. Sci. Children 25(7):22-24.

Relf, D., A.R. McDaniel, and B. Butterfield. 1992. Attitudes toward plants and gardening. HortTechnology 2:201-204.

Salisbury, J. 1989. New Alchemy's green classroom. New Alchemy Quart. 35:4-6.

Shair, G. 1999. A history of children's gardens. Public Garden July/August/September:9-11.

Skelly, S.M. and J.M. Zajicek. 1998. The effect of an interdisciplinary garden program on the environmental attitudes of elementary school students. Hort Technology 8:579-583.

Stetson, E. 1991. The big green schoolhouse. Educ. Leadership 18:34-35.

Trobe, H.L. and T.G. Acott. 2000. A modified NEP/DSP environmental attitudes scale. J. Environ. Educ. 32(1):12-20.

Trochim, W.M. 2001. Likert scaling. 29 Nov. 2001. <http://trochim.human. cornell.edu/kb/scallik.htm>.

Waliczek, T.M. and J.M. Zajicek. 1999. School gardening: Improving environmental attitudes of children through hands-on learning. J. Environ. Hort. 17:180-184.

Welsh, D.F., L.A.Whittlesey, R.L. Seagraves, G.W. Hall, and M.M. Harlow. 1999. Junior Master Gardeners program addresses youth needs. J. Ext. 37(3). 6 Oct. 2004 <http://joe.org/joe/1999june/ iwl.html>. 